\title{
THERMO-MECHANICAL ANALYSIS OF BIO-BASED HYBRID NANOCOMPOSITES FOR BRAKE PAD APPLICATION
}

\section{OLUWAFEMI E. IGE*, FREDDIE L. INAMBAO, OLUWATOYIN J. GBADEYAN}

Department of Mechanical Engineering, University of KwaZulu-Natal, Durban, South Africa

\begin{abstract}
In this study, a friction material filled with carbon nanospheres (CNSs) was developed and tested. The CNSs were produced by simple physical activation under a nitrogen atmosphere. Bio-based hybrid nanocomposite (BHN) brake pads were produced and their thermo-mechanical properties were assessed. In this work, friction nanocomposite materials that were varied with carbon nanospheres were developed with different parameters. Thermo-mechanical properties of the BHN brake pads developed were assessed, such as compressive strength, impact strength, dynamic mechanical analysis (DMA) and thermo-gravimetric analysis (TGA). The BHN brake pad samples were compared with control (CONTR). Subsequently, a scanning electron microscopy (SEM) study was performed on the brake pads fracture surfaces. From the SEM images, micro-cracks were noticed on BHN 4 and BHN 5 fractured surfaces while surface degradation was observed on BHN 1 and an interlocking structure observed on BNH 3 and BHN 6. The results showed a uniform distribution of carbon nanospheres that supported impact stress resistance results. This structural formation improved the inner hardness of BHN brake pads, thus improving the breaking fracture resistance. TGA showed the loading of CNS improved thermal stability of friction nanocomposites. The CONTR and BHN brake pads had similar thermal stability and degradation temperatures. The results showed that the BHN exhibited excellent mechanical properties compared to CONTR.

KEYWORDS: CNS, Mechanical Analysis, Friction Materials, TGA, DMA.
\end{abstract}

Received: Jan 03, 2021; Accepted: Jan 23, 2021; Published: Mar 08, 2021; Paper Id.: IJMPERDAPR202113

\section{INTRODUCTION}

In the last two decades the formulation of brake pad materials has undergone significant changes due to health problems related to the asbestos brake pad, and a meaningful effort has been made to develop high-performance non-asbestos brake pad materials from agricultural waste [1-4] and composite materials [5-7]. Automobile brake pads are ubiquitous, so the materials used in the development of such products need to be carefully selected to reduce their impact on health and the environment [8-13]. Globally, material researchers and formulation designers are involved in developing multi-phased friction composite material, i.e., combinations of filler, fibers, binders and friction modifiers that meet quality requirements, as automotive braking technology continues to improve [14, 15]. The primary use of a binder is to hold the various components of the brake pad together and to prevent the decomposition of its components [16-18]. In essence, fillers are used to reduce the total cost of the material and effectively improve the brake pad properties [19]. Composite materials help researchers modify the existing materials, making them more suitable and consistent, thereby developing a suitable substitute for the existing materials. According to reports by [20], [21], [22], and [23], the use of various decision-making techniques and models to optimize the friction composite materials can be used to improve the design of friction formulations for standard performance objectives. Today, hybrid polymer composites material are being studied globally and 
becoming potential alternative materials in producing different components, products, and parts in industrial applications $[24,25]$.

The manufacturing of friction materials need to meet specific thermo-mechanical requirements [9, 26-31]. Braking friction materials must have good wear resistance, stable friction, low noise, and damping over a wide range of temperature, pressure, and speed [15, 32]. Maintaining stable performance in terms of friction, wear, fade, and recovery under a wide variety of operating conditions is the main attribute of the friction composite materials [15].

Thermo-gravimetric analysis and differential scanning calorimetric (TGA, DSC) have been used to study the thermal behavior of materials [33]. The thermal analyser machine is used to calculate the heat flow (differential scanning calorimetry) and the weight loss (thermo-gravimetric) in the material with respect to temperature and time. The data obtained from TGA is used to distinguish between endothermic measurements that are not associated with weight loss and exothermic measurements that are associated with weight loss [34]. When assessing the thermal behavior of the brake pad, the methodology described above is applicable to this study. The determination of thermal properties, compressive strength, impact strength and dynamic mechanical analysis (DMA) are suitable for this study, especially to determine the performance of braking and stopping force of the hybrid brake pads.

A new BHN brake pad has been developed which is a mixture of nanoscale carbon-based materials and has been employed to produce brake pads. The work investigates the thermo-mechanical properties of BHN friction materials.

\section{EXPERIMENT}

\section{Materials}

ATM Composite in Durban, South Africa, supplied the BHN materials based on a neat epoxy resin of LR 20 type without modification which was used as a binder. The carbon nanospheres (CNSs) were produced by simple physical activation under nitrogen atmosphere (catalyst-free) at the Department of Chemistry, University of Zululand, South Africa. Stainless steel nanoparticles and graphite nanoparticles were purchased from Capital Lab supplies, Durban, South Africa. These materials were added together to make $100 \%$ by weight to the produced BHN brake pads as shown in Table 1. Each nanosphere was about $10 \mathrm{~nm}$ to $60 \mathrm{~nm}$ in diameter [35].

Prior to the production of the BHN brake pad, epoxy resin was weighed and heated to a temperature of $70{ }^{\circ} \mathrm{C}$ in a beaker to reduce the viscosity and facilitate the dispersion of other components. The components were mixed using a mechanical stirrer for one hour at $500 \mathrm{rpm}$ to attain a homogenous mixture.

Table 1: Bio-Based Hybrid Nanocomposite Formulation

\begin{tabular}{|c|c|c|c|c|c|}
\hline \multirow{2}{*}{ Samples } & \multicolumn{5}{|c|}{ Composite in Weight Percentage (wt. \%) } \\
\cline { 2 - 6 } & Binder & $\begin{array}{c}\text { Graphite } \\
\text { Nanoparticles }\end{array}$ & $\begin{array}{c}\text { Carbon Nano- } \\
\text { Spheres }\end{array}$ & $\begin{array}{c}\text { Stainless Steel } \\
\text { Nanoparticles }\end{array}$ & Total (\%) \\
\hline BHN 1 & 98.1 & 1 & 0.1 & 0.8 & 100 \\
\hline BHN 2 & 98.6 & 0.3 & 0.3 & 0.8 & 100 \\
\hline BHN 3 & 98 & 1 & 0.2 & 0.8 & 100 \\
\hline BHN 4 & 98.6 & 0.5 & 0.1 & 0.8 & 100 \\
\hline BHN 5 & 97.9 & 1 & 0.3 & 0.8 & 100 \\
\hline BHN 6 & 98.7 & 0.3 & 0.2 & 0.8 & 100 \\
\hline
\end{tabular}




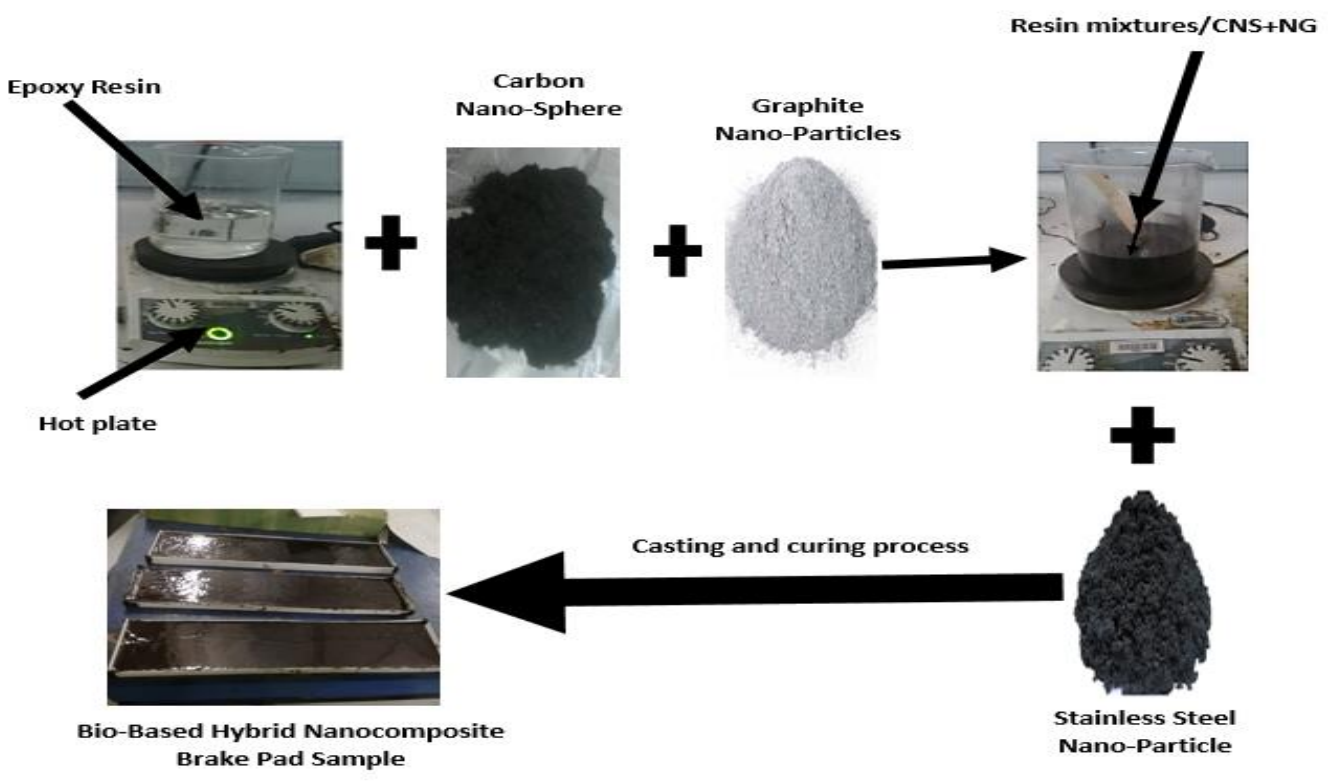

Figure 1: Bio-based Hybrid Nanocomposite Brake Pad Process Overview

The BHN material was achieved at room temperature and mixed with 100 vol.\% to 30 vol.\% of catalyst to improve the curing process. Stainless steel nanoparticles ( $8.0 \mathrm{wt} . \%)$ were added to the different compositions, as shown in Figure 1. The plastic mold was waxed before the material was poured into the mold for easy removal of the BHN sample after two days. After curing for 14 days, the samples were tested.

\section{MECHANICAL PROPERTIES}

\section{Compressive Strength}

The compressive strength of a material is the ability of the material to resist fracture under compression. The compressive properties of the BHN brake pads were calculated according to a standard specification of the ASTM D 695 tests [36]. A Lloyd Universal Testing Machine equipped with a $30 \mathrm{kN}$ load cell was used to test the samples as shown in Figure 2 . A rectangular test sample with width, thickness, and dimensional length of $12.7 \mathrm{~mm}$ x $12.7 \mathrm{~mm} \times 57.0 \mathrm{~mm}$ was cut from the developed biobased hybrid nanocomposite using a diamond-cutting machine. Before testing, sandpaper was used to smooth any sharp edges of the samples left by the diamond-cutting machine.

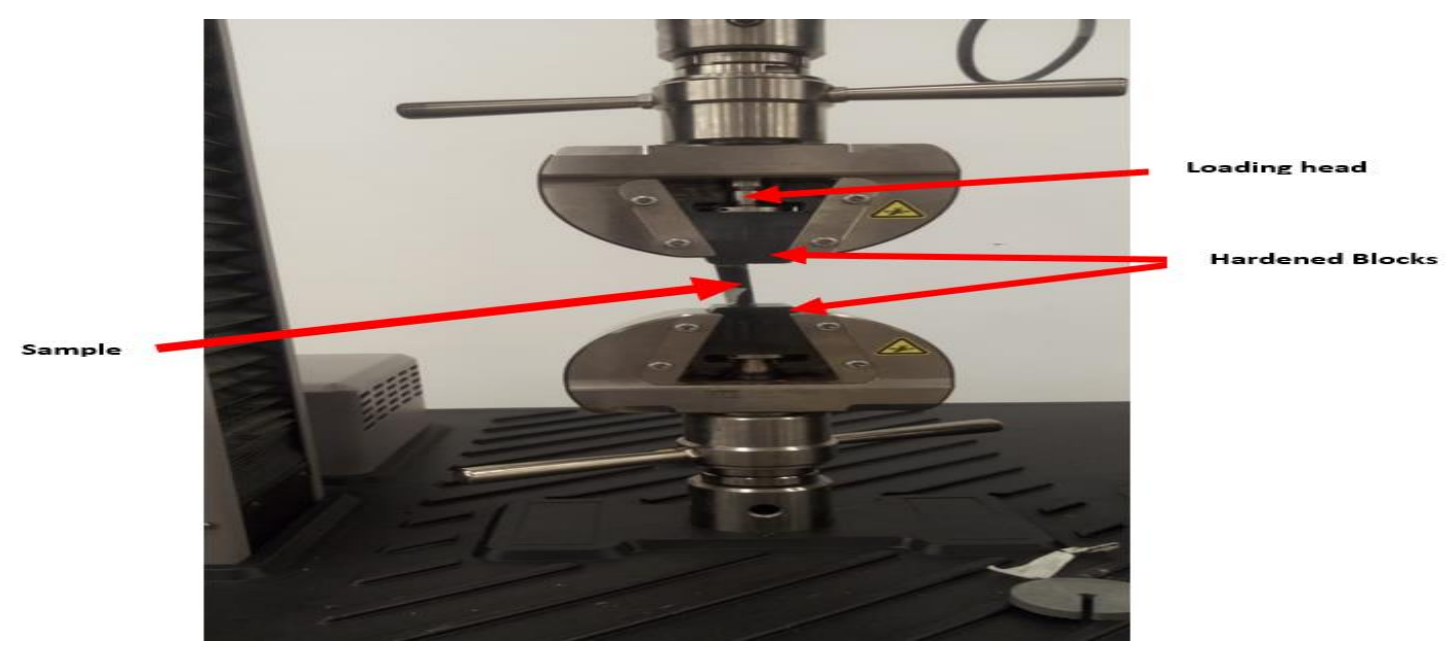

Figure 2: Compressive Test with Hardened Blocks on Lloyd Testing Machine 
The test sample was gripped directly between the compression plates prepared in the moveable crosshead, and the bottom crosshead blocks were compressed before gauge failure. After proper positioning and tightening of the sample between the compression plates, the load was applied, and the compressive strain was examined from the display output. The load was applied slowly to the sample, and at regular intervals the corresponding strain was recorded. The six samples were tested at ambient temperature with a test speed of $1.3 \mathrm{~mm} \pm 0.3 \mathrm{~mm}$ ( 0.050 inches \pm 0.010 inches $) / \mathrm{min}$. The average value was used for graphical representation, and a discussion of the six samples was reported. The following equation was used to calculate compressive strength, strain, and modulus.

$\sigma_{e}=\frac{F^{*}}{A^{\circ}}$

$\varepsilon_{e}=\frac{\left(l_{\circ}-l^{*}\right)}{l_{\circ}}$

$E=\frac{\sigma_{2}-\sigma_{1}}{\varepsilon_{2}-\varepsilon_{1}}$

$l_{\text {.: }}$ Original gauge length $(\mathrm{mm})$

$A^{\circ}$ : Original cross-sectional area of the sample in the gauge length $\left(\mathrm{mm}^{2}\right)$

$F^{*}$ : Maximum load applied before crushing $(\mathrm{N})$

$\sigma_{e}$ Compressive strength

$l^{*}$ : Specimen length after crushing $(\mathrm{mm})$

$\sigma_{1}, \sigma_{2}$ : Corresponding stress at the specific strain (MPa)

$\varepsilon_{1}, \varepsilon_{2}$ : Corresponding stress at the specific stress (MPa)

$E$ : Compressive modulus (MPa)

\section{Impact Strength}

The impact resistance of developed bio-based hybrid nanocomposite and conventional brake pads was determined by conducting a Charpy test at room temperature using the Hounsfield Balance Impact Tester produced by Tensometer Ltd. Croydon, United Kingdom. The Hounsfield Balance Impact Machine is made according to the ASTM D6110-10 standard with a three-point to Charpy device [121]. The geometric size of the sample cut from the brake pad was $50 \mathrm{~mm}^{3} \times 10 \mathrm{~mm}^{3} \times$ $5 \mathrm{~mm}^{3}$ i.e., length, width, and thickness. This method allowed the samples' width to vary according to the different materials (either brittle or ductile). All samples had a $4 \mathrm{~mm}$ deep mark at the center part opposite the impact part, and the impact width area was $6 \mathrm{~mm}$. The six samples were examined for brake pad formation, and the impact speed was about 6.7 $\mathrm{m} / \mathrm{s}$. The average collected value was used to determine the energy absorption using the following formula:

$I S=\frac{A E}{W T}$

IS: Impact strength $(\mathrm{KJ} / \mathrm{m} 2)$

$A E$ : Absorbed energy (Joule)

$W$ : Remaining width at the notch (m)

$T$ : Specimen thickness (m) 


\section{Scanning Electron Microscopy (SEM)}

After the impact test, the BHN brake pad fracture surfaces were examined with scanning electron microscopy (SEM) using EVO HD 15 model produced by Carl Zeiss Environmental SEM operating 1000 times zoom under atmospherically controlled conditions at $20 \mathrm{kV}[19,37,38]$. The samples were coated with an ultra-thin gold film before microstructure analysis.

\section{THERMAL ANALYSIS}

The thermo-mechanical properties of the BHN samples were investigated using dynamic mechanical analysis (DMA), while the BHN samples' thermal behavior was studied using a (TGA). The TGA test aimed to determine the thermal stability, temperature degradation, and heat energy absorption of each brake pad.

\section{Thermo-Gravimetric Analysis (TGA)}

The TGA testing was conducted under a dry nitrogen gas flow rate of $100 \mathrm{~mL} / \mathrm{min}$ from $20^{\circ} \mathrm{C}$ to $600{ }^{\circ} \mathrm{C}$ and a $100{ }^{\circ} \mathrm{C} / \mathrm{min}$ heating rate. The thermal stability and degradation of the BHN samples were measured using the thermal analyser instrument SDT Q600 V20.9 Build 20. TGA is a widely used thermal analytical technique for determining thermal stability, ash content, etc., related to composite materials. TGA calculates the weight loss of the sample in relation to the temperature.

\section{Dynamic Mechanical Analysis (DMA)}

The thermo-mechanical properties of the BHN brake pads were investigated using DMA to determine the storage modulus (E'), loss modulus (E"), and tan-delta (Tan $\delta$ ) in relation to temperature scanned. The DMA of each BHN sample was examined using TA instrument DMA (model Q800 V21.2 Build 88) following the ASTM E1867 standard at the frequency of $10 \mathrm{~Hz}$ under three-point bending mode from $20{ }^{\circ} \mathrm{C}$ to $190{ }^{\circ} \mathrm{C}$ under atmospheric conditions with the temperature scan [39]. The sample size of $5.5 \mathrm{~cm} \times 1.2 \mathrm{~mm} \times 0.35 \mathrm{~cm}$ was examined [40].

\section{RESULTS AND DISCUSSION}

\section{Compressive Properties}

The compressive strength of BHN and the control (CONTR) brake pads are presented in Table 2. It can be seen that BHN 1, BHN 2 BHN 3, BHN 5, and BHN 6 brake pads had a higher compressive strength compared to CONTR, while sample BHN 4 did not. Sample BHN 2 exhibited $43.7 \%$ higher compressive strength than CONTR; this improvement could be due to nanoparticles and nanosphere in the composition.

Table 2: Compressive Strength of BHN and Control Brake Pads

\begin{tabular}{|c|c|c|}
\hline $\begin{array}{c}\text { Bio-Based Hybrid } \\
\text { Nanocomposite }\end{array}$ & $\begin{array}{c}\text { Compressive Strength } \\
\text { (MPa) }\end{array}$ & $\begin{array}{c}\text { Remarks } \\
(\%)\end{array}$ \\
\hline CONTR & 3000,1 & \\
\hline BHN 1 & 3410,3 & 13,7 \\
\hline BHN 2 & 4311,4 & 43,7 \\
\hline BHN 3 & 3896,3 & 29,9 \\
\hline BHN 4 & 1772,6 & $-40,9$ \\
\hline BHN 5 & 3771,4 & 25,7 \\
\hline BHN 6 & 3557,3 & 18,6 \\
\hline
\end{tabular}


As shown in Figure 3, it was noticed that there was a different compressive strength for each brake pad formulation. The bond between the quantity and the constituent type affects the composite strength and influences the final properties [41]. Given this aspect, in the formulation of each brake pad, the inconsistent compressive strength shown in Figure 3 can be attributed to the different content of the additives.

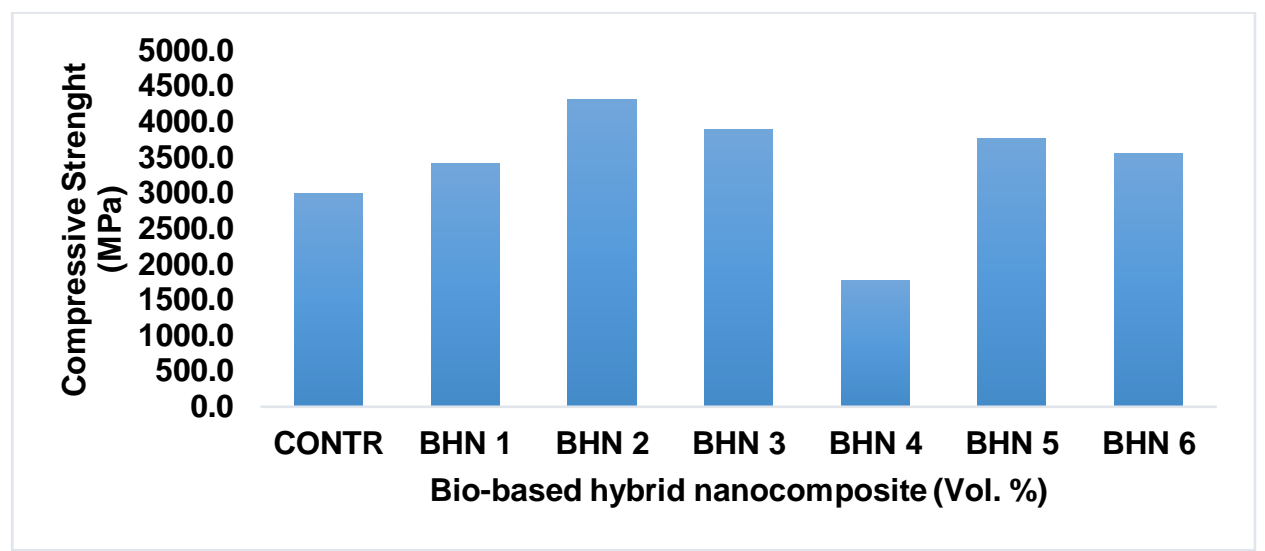

Figure 3: Compressive Strength of the BHN and CONTR Brake Pads

The higher loading of graphite nanoparticles, therefore, resulted in lower compressive strength of the BHN 4 sample. In conclusion, strength was affected by better bonding of brake pad additives. The compressive strength of the BHN brake pads sample filled with $0.3 \%$ CNSs improved with an increase in CNS content. Although the CNS content of BHN 3, BHN 5, and BHN6 brake pads increased, BHN 2 showed the highest strength.

This improved strength meant that BHN 2 had a greater resistance to force than other BHN and CONTR brake pads. The damage caused by compressive stress and the failure that accompanied this manifested as delamination and fracture of brake pad additives.

\section{Impact Properties}

Table 3 indicates the impact strength of the BHN and CONTR brake pads computed on the Charpy impact tester. Figure 4 shows the impact fractures of both developed BHN and CONTR brake pads. It was noted that, except for BHN 1, BHN 2, and BHN 5, the BHN brake pads had better impact resistance than the CONTR brake pad. The reduction in the impact strength of BHN 1, BHN 2, and BHN 5 may be due to the agglomeration produced by high loading graphite nanoparticle. The impact resistance of BHN brake pads varied with their composition. The impact resistance of BHN 4 was highest at $4.1 \mathrm{KJ} / \mathrm{m}^{2}$, which was $35.1 \%$ higher than the CONTR brake pad impact value of $3.0 \mathrm{KJ} / \mathrm{m}^{2}$. The improvement in impact strength can be credited to the interlocking bond produced by the additives, which ultimately improved the energy absorption capacity.

Table 3: Impact Strength of BHN and CONTR Brake Pads

\begin{tabular}{|c|c|c|}
\hline & Impact Strength $\left(\mathbf{K J} / \mathbf{M}^{\mathbf{2}}\right)$ & Remarks (\%) \\
\hline CONTR & 3,0 & \\
\hline BHN 1 & 2,9 & $-2,5$ \\
\hline BHN 2 & 2,9 & $-4,6$ \\
\hline BHN 3 & 3,4 & 11,7 \\
\hline BHN 4 & 4,1 & 35,1 \\
\hline BHN 5 & 2,8 & $-8,0$ \\
\hline BHN 6 & 3,3 & 8,7 \\
\hline
\end{tabular}




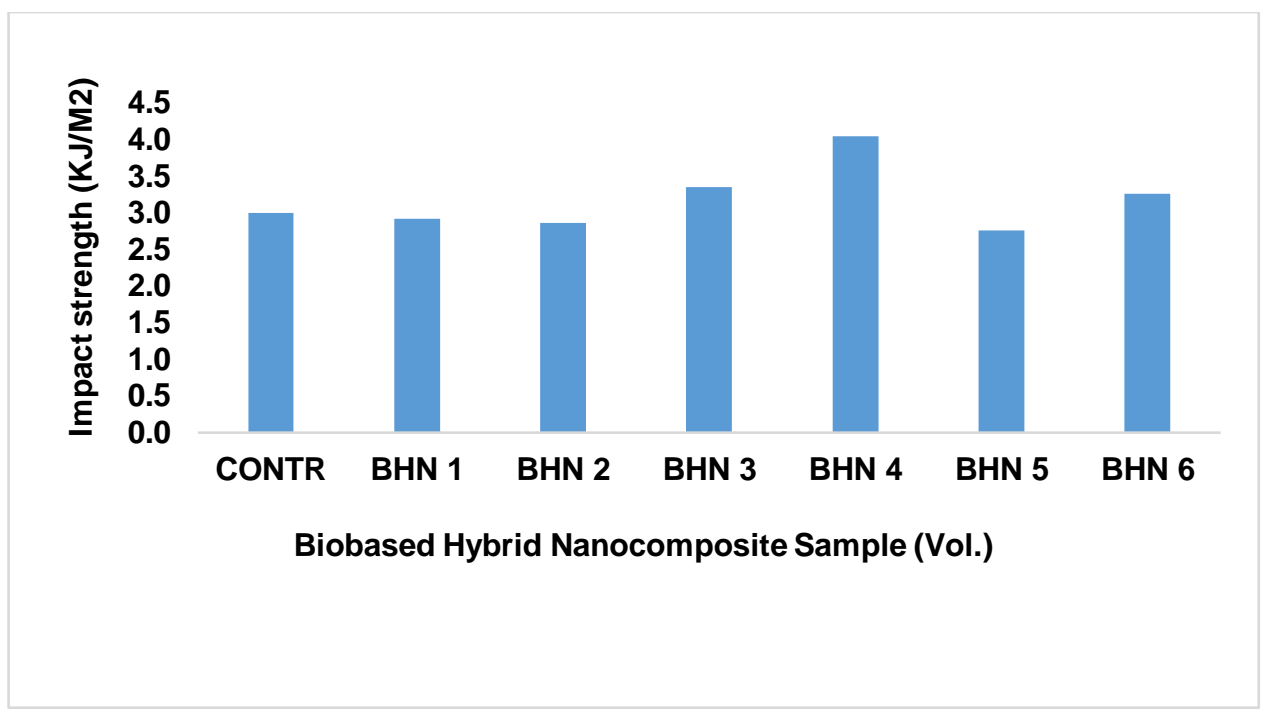

Figure 4: The Impact Fracture Resistance of CONTR and BHN

Subsequently, SEM testing was carried out to determine the brake pad impact failure. Figures 5a to $5 \mathrm{~g}$ present the SEM micrographs captured for the BHN and CONTR brake pads fracture surfaces at 2500X magnification. The CONTR brake pad fracture surface exhibits disintegration of the composition, porosity, and surface degradation, causing cracks on the CONTR impact surface. These structures indicated a brittle failure and were consistent with the impact value presented in Table 3. However, the trend of BHN brake pads is the opposite, as the fractured surface were together with the hard fracture surface. A uniform distribution of carbon nanosphere was observed, supporting the impact stress resistance results. This structure improved the inner hardness of BHN brake pads, thus improving the breaking fracture resistance.

As shown in Figures 5a to 5g, micro-cracks were noticed on BHN 4 and BHN 5. Surface degradation was observed on BHN 1 and interlocking structure on BNH 3 and BHN 6. These may be due to fiber matrix or additive accumulation at a certain point in the matrix, leading to delamination and reduction in the strength of the BHN brake pads. As the fiber loading increased, the fiber interface reduced. Therefore, it reduced the impact strength, as shown in Table 3.

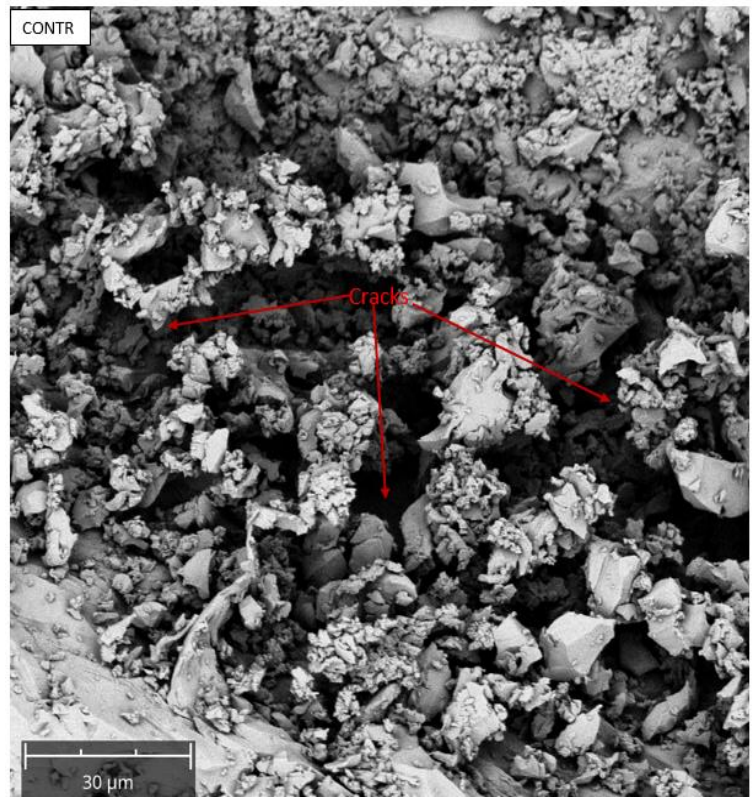

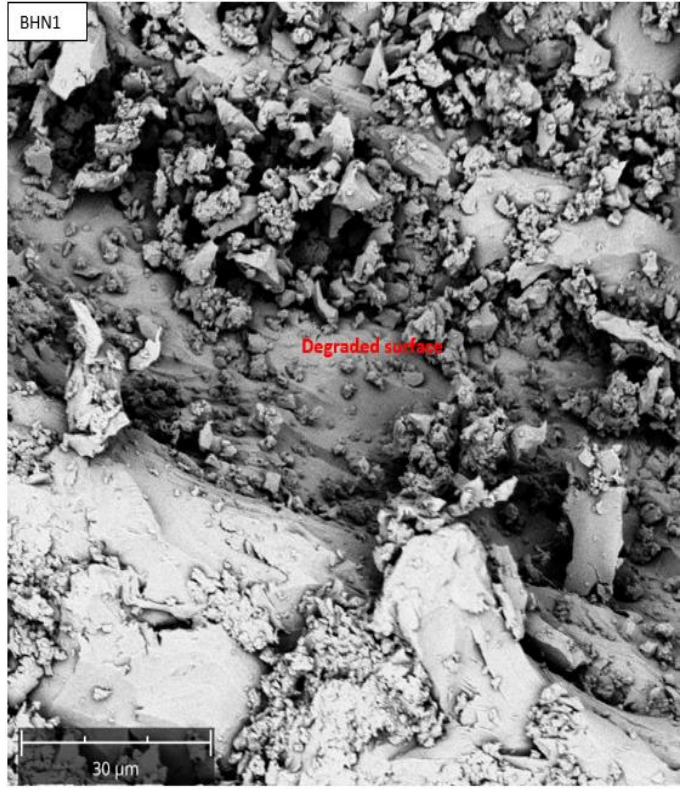

b 

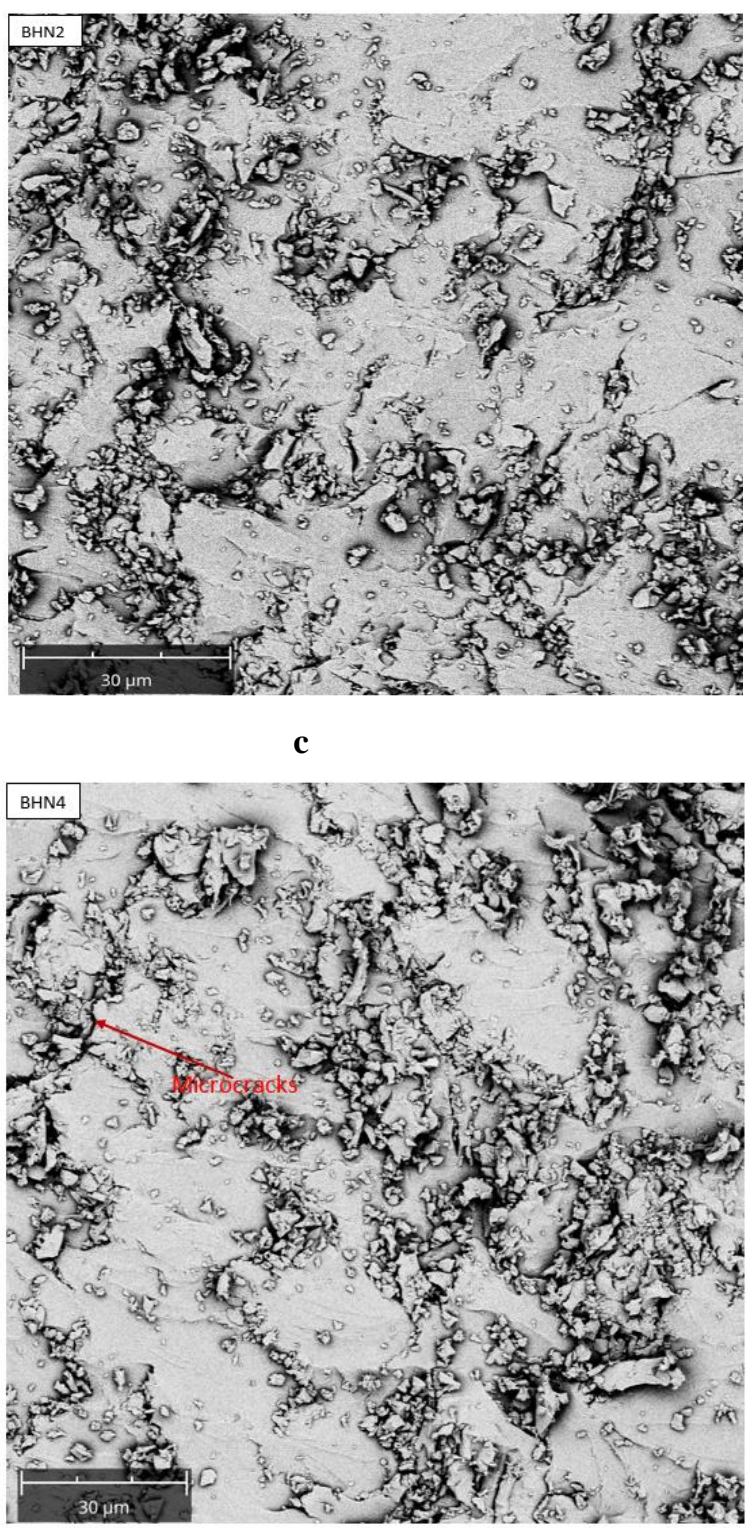

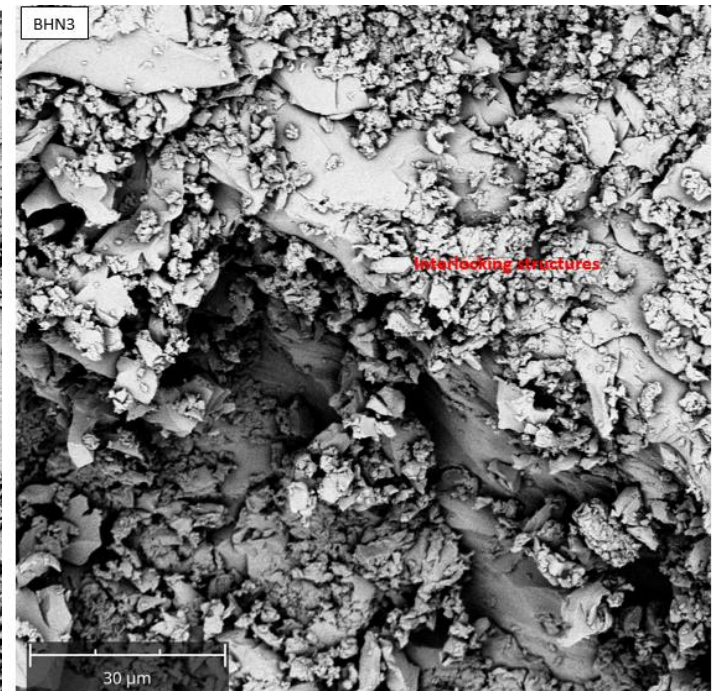

d

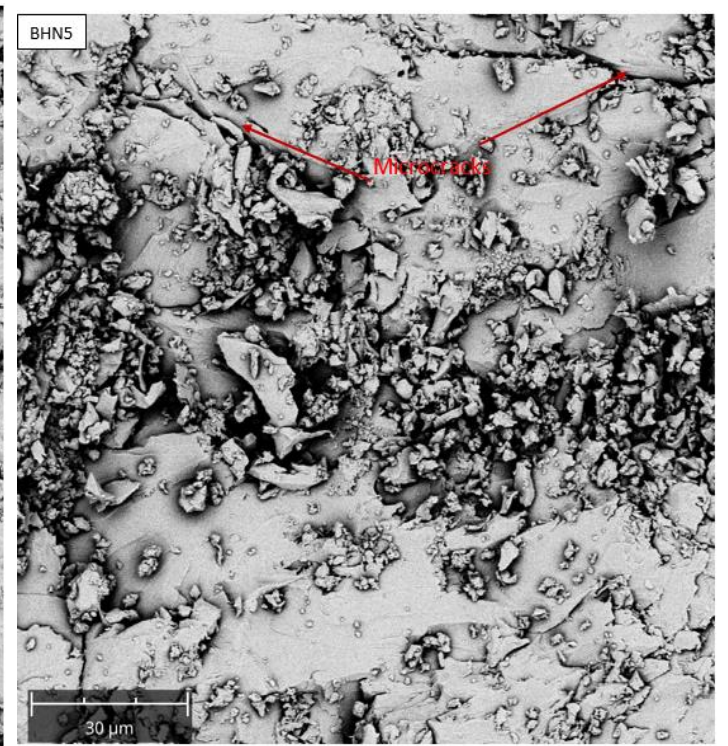

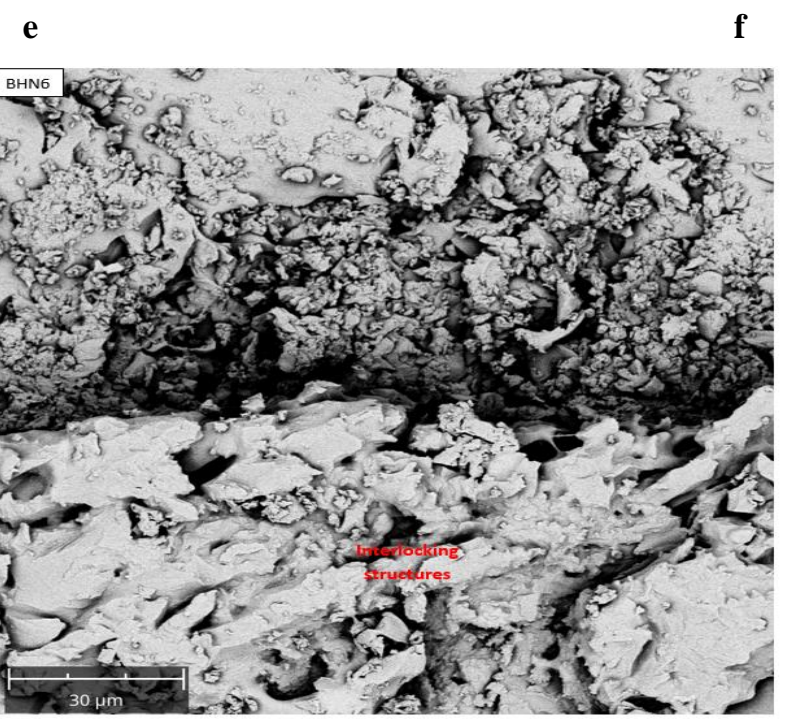

g

Figure 5 a to g: The SEM Micrograph of the BHN and CONTR brake Pads Impact Fracture Surfaces 
BHN 2 shows a tough fractured surface with a uniform mixture of ingredients filled together. This structure forms an interface bond with increased carbon content, which is in line with the excellent impact resistance recorded in Table 3. Therefore, the total energy needed to break the BHN brake pad resulted from the interfacial bond present between the binder and other additives. Hence, the improvement of fracture resistance at which the BHN brake pad broke can be credited to the carbon-based filler loading properties, the binder adhesive qualities, and interactive functions of the carbonbased ingredients.

\section{Thermo-Gravimetric Analysis (TGA)}

In respect to the time and temperature, the thermo-gravimeter was used to calculate the weight loss, while differential scanning calorimetry was used to measure the differential heat flow in the material. The thermal stability and degradation of BHN brake pads were studied using TGA, as shown in Figure 6. The results show that the CONTR and BHN brake pads had similar thermal stability and degradation temperatures. This output could be due to the characteristics of the thermal properties in the CNS and graphite nanoparticles in the formulations of the brake pads.

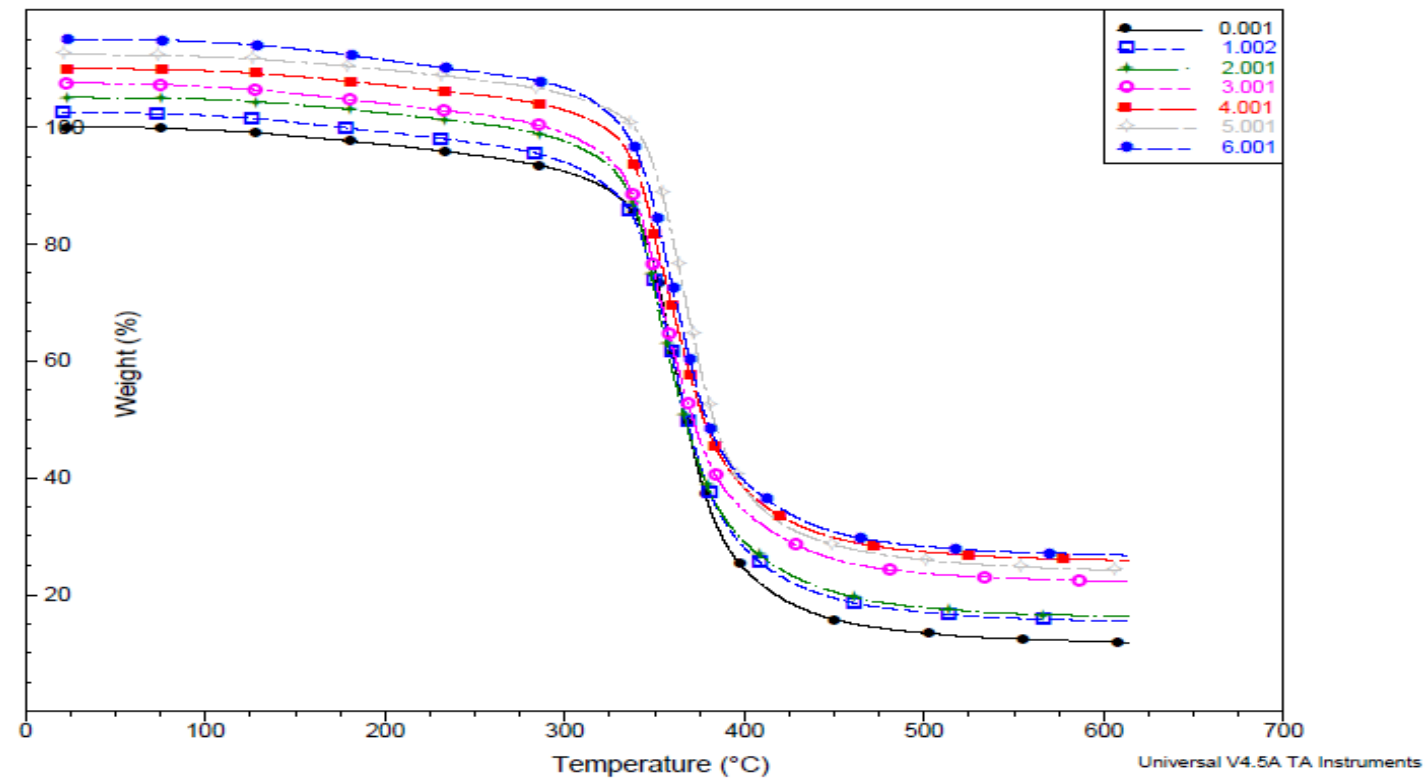

Figure 6: TGA curve of the BHN as a Function of Temperature

\subsection{1 (CONTR), 1.002 (BHN 1), 2.001 (BHN 2), 3.001 (BHN 3), 4.001(BHN 4), 5.001 (BHN 5), 6.001 (BHN 6)}

It is also evident from Figure 6 that the weight loss increased with an increase in temperature. It can be understood from the figure that the decomposition temperatures varied according to the different brake pad formulations. These results show that the graphite nanoparticle loading in the formulations impacted the BHN brake pads' decomposition temperature. The BHN brake pad sample with $0.3 \%$ of graphite nanoparticle had a better degradation compared to others. However, the loading of CNS content positively impacted the BHN brake pads with 0.3 vol. $\%$ and 0.3 vol. $\%$ graphite nanoparticles. The BHN samples had better thermal stability as the CNS content increased accordingly.

The weight loss appeared in three phases. The thermal image of the BHN and CONTR formulation presented in Figure 6 shows that all nanocomposite materials had a gradual decomposition rate at the first stage, and the thermal stability was approximately $98 \%$. The first weight loss in all friction nanocomposites was very low. About $2 \%$ weight loss occurred at $50{ }^{\circ} \mathrm{C}$ to $350{ }^{\circ} \mathrm{C}$ related to the sample water and gas. After that, the decomposition rate accelerated as the 
vertical negative slope curve at the second stage became sharper and sharper, and the thermal stability was approximately $74 \%$. The second weight loss was around $20 \%$ to $30 \%$ at about $350{ }^{\circ} \mathrm{C}$ to $400{ }^{\circ} \mathrm{C}$ due to hemicellulose thermal depolymerization and resin degradation, and the rate of degradation/decomposition was much faster. The decomposition rate changed more gradually at the third stage with an average of $78 \%$ thermal stability.

The third weight loss was about $3 \%$ and happened in the range $400{ }^{\circ} \mathrm{C}$ to $600{ }^{\circ} \mathrm{C}$ and was due to more decomposition. At temperatures above $400{ }^{\circ} \mathrm{C}$, due to the intersection of degradation curves, an increase in thermal stability of BHN 2 and BHN 5 was observed with a greater quantity of carbon-carbon additives becoming more dominant in thermal stability. The TGA curve showed that adding CNS to the resin matrix greatly improved the materials' thermal stability, but CONTR also showed excellent thermal stability. This thermal stability improvement can be due to the thermal properties of carbon-based additives, which have impeded the distribution of volatile decomposition from the matrix. This output is consistent with the studies by Krump et al. and Duquesne et al. [42-44], where volatile degradation products adsorbed from the surface of the material improved thermal stability.

Table 4: TGA of the BHN Brake Pad Friction Material

\begin{tabular}{|c|c|c|c|}
\hline \multirow[t]{2}{*}{$\begin{array}{l}\text { Bio-Based Hybrid } \\
\text { Nanocomposite }\end{array}$} & \multicolumn{3}{|c|}{$\begin{array}{l}\text { Thermal Stability (\%) with Respect to Temperature } \\
\qquad\left({ }^{\circ} \mathrm{C}\right)\end{array}$} \\
\hline & $50^{\circ} \mathrm{C}$ to $350^{\circ} \mathrm{C}$ & $350^{\circ} \mathrm{C}$ to $400^{\circ} \mathrm{C}$ & $400{ }^{\circ} \mathrm{C}$ to $600^{\circ} \mathrm{C}$ \\
\hline CONTR & 95,35 & 44,81 & 14,73 \\
\hline BHN1 & 94,99 & 43,66 & 15,81 \\
\hline BHN2 & 95,51 & 40,58 & 14,22 \\
\hline BHN3 & 94,79 & 42,57 & 17,55 \\
\hline BHN4 & 95,68 & 45,54 & 18,66 \\
\hline BHN5 & 96,16 & 49,79 & 14,84 \\
\hline BHN6 & 94,99 & 42,86 & 14,66 \\
\hline
\end{tabular}

Table 4 shows the average thermal stability (\%) of the BHN brake pad and CONTR at three different temperature zones $\left(50{ }^{\circ} \mathrm{C}\right.$ to $350{ }^{\circ} \mathrm{C}, 350{ }^{\circ} \mathrm{C}$ to $400{ }^{\circ} \mathrm{C}$, and $400{ }^{\circ} \mathrm{C}$ to $600{ }^{\circ} \mathrm{C}$ ), illustrated in Figure 6. The BHN brake pads and CONTR brake pad exhibit similar thermal degradation in all three temperature zones.

\section{Dynamic Mechanical Analysis}

The dynamic mechanical properties such as storage modulus (E'), loss modulus (E"), and damping factor or tan-delta (Tan $\delta$ ) of the bio-based hybrid nanocomposite materials were investigated as a function of temperature as shown in Figures 7 to 9 . This function makes it possible to understand the loss in mechanical, physical, and tribological properties with increased temperature, which can be due to modulus loss [45, 46]. Figure 7 shows the characteristics of the BHN storage modulus. All the BHN samples remained high in the temperature range $20^{\circ} \mathrm{C}$ to $55^{\circ} \mathrm{C}$ and followed $\mathrm{E}^{\prime}$ magnitude, BHN 6, BHN 5, BHN 4, BHN 3, BHN 2, BHN 1, and CONTR. 


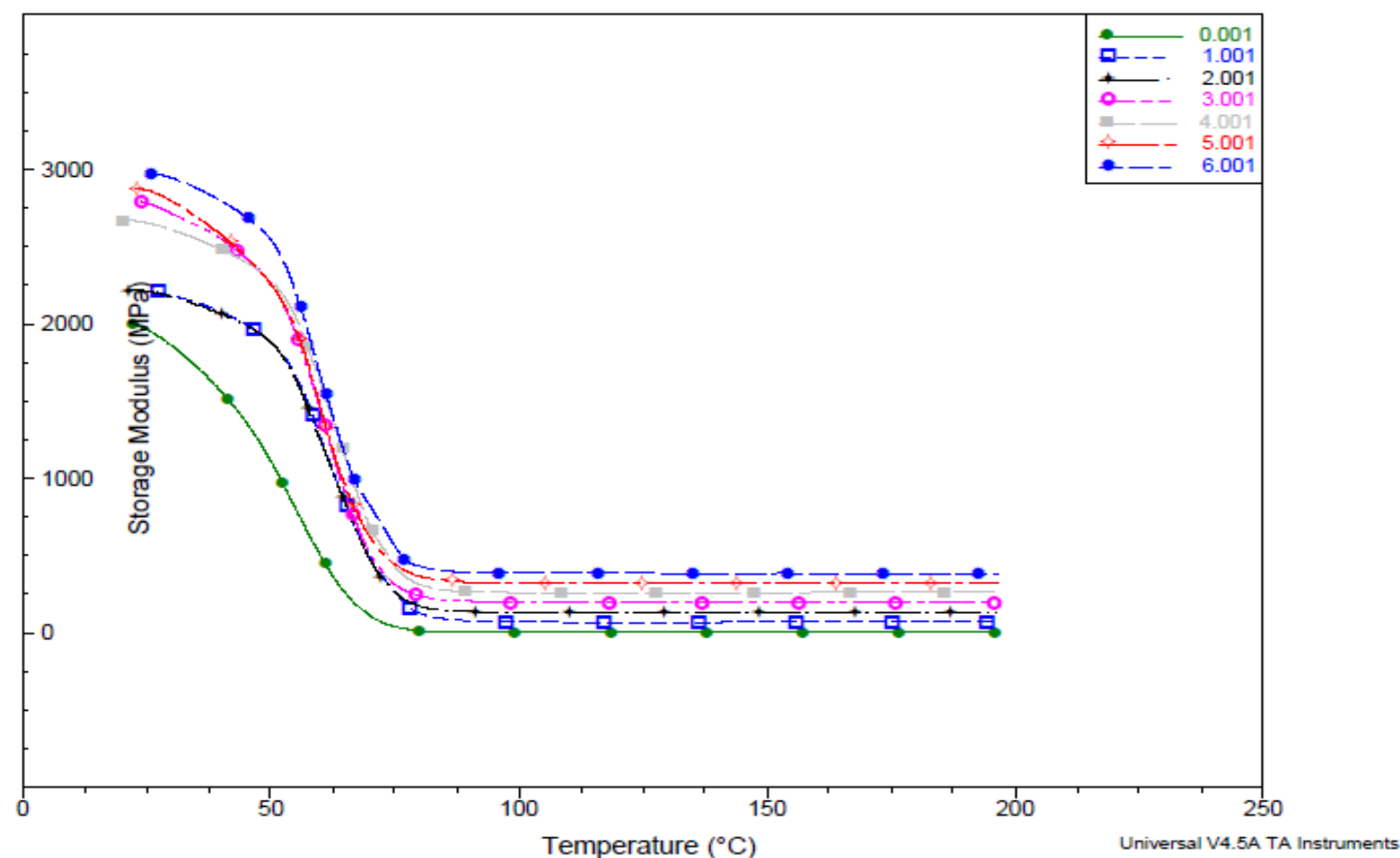

Figure 7: Storage Modulus of the BHN as a Function of Temperature

0.001 (CONTR), 1.001 (BHN 1), 2.001 (BHN 2), 3.001 (BHN 3), 4.001(BHN 4), 5.001 (BHN 5), 6.001 (BHN 6)

There was a steady storage modulus loss at an estimated comparable rate as temperature increased. This outcome could be because of the breaking or weakening of the molecular bonds between various polymeric chains, resulting in weakening of the structure. The material appears to exhibit viscous performance in the temperature range $50{ }^{\circ} \mathrm{C}$ to $70{ }^{\circ} \mathrm{C}$, as established by loss modulus curves shown in Figure 8. Thus, the variation of graphite nanoparticles in the samples improved the modulus throughout the formulation. The BHN samples appear to lose their functional properties at a higher temperature. The functionality of the samples nearly finished at the temperature range $80{ }^{\circ} \mathrm{C}$ to $190{ }^{\circ} \mathrm{C}$. It can be seen that the loss modulus remained low within the temperature range of about $20^{\circ} \mathrm{C}$ to $55^{\circ} \mathrm{C}$ as the storage modulus is still in the dominant position throughout the formulation, as shown in Figure 7.

The characteristics of the loss modulus of the BHN material studied are illustrated in Figure 8. At temperatures between $50^{\circ} \mathrm{C}$ to $70^{\circ} \mathrm{C}$, the loss modulus increased exponentially compared to the sharp fall in the storage modulus. The increase was in BHN 6, BHN 5, BHN 4, BHN 3, BHN 1, BHN 2, and CONTR. It was also observed that the viscous zone temperature moved marginally towards the low-temperature side with a rise in the variation of graphite nanoparticles reinforcement. 


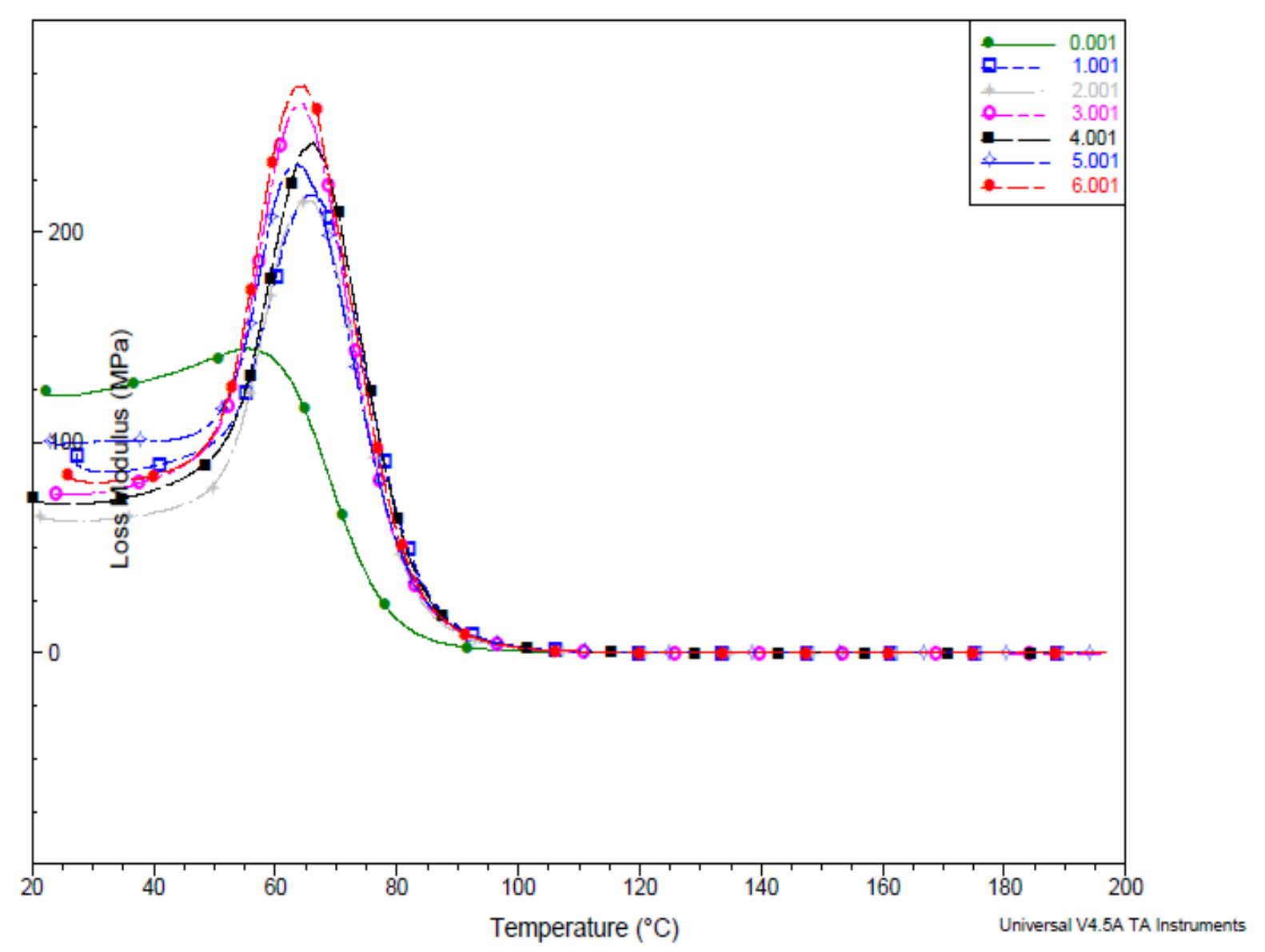

Figure 8: Loss Modulus of the BHN as a Function of Temperature

0.001(CONTR), 1.001 (BHN1), 2.001 (BHN2), 3.001 (BHN3), 4.001(BHN4), 5.001 (BHN5), 6.001 (BHN6)

At a temperature of between $90{ }^{\circ} \mathrm{C}$ and $190{ }^{\circ} \mathrm{C}$, all the material failed and resulted to zero loss modulus. The Tan $\delta$ loss evaluates the energy lost within the material during the damping process. The characteristics of damping or Tan $\delta$ of the BHN materials studied are illustrated in Figure 9. The higher the value of $\operatorname{Tan} \delta$, the better the damping capacity of the friction materials. Figure 9 showed similar temperatures between $20^{\circ} \mathrm{C}$ to $55^{\circ} \mathrm{C}$ and a similar plot, i.e., CONTR, BHN 6, BHN 5, BHN 4, BHN 3, BHN 2, and BHN 1 storage modulus and loss modulus. It was observed that within the temperature range $20^{\circ} \mathrm{C}$ to $55^{\circ} \mathrm{C}$, $\operatorname{Tan} \delta$ had a lower magnitude throughout the formulation, which was due to the supremacy of the storage modulus over the loss modulus. At a temperature range between $55^{\circ} \mathrm{C}$ and $105^{\circ} \mathrm{C}$, the $\operatorname{Tan} \delta$ magnitude of BHN was higher due to the supremacy of the loss modulus over the storage modulus. 


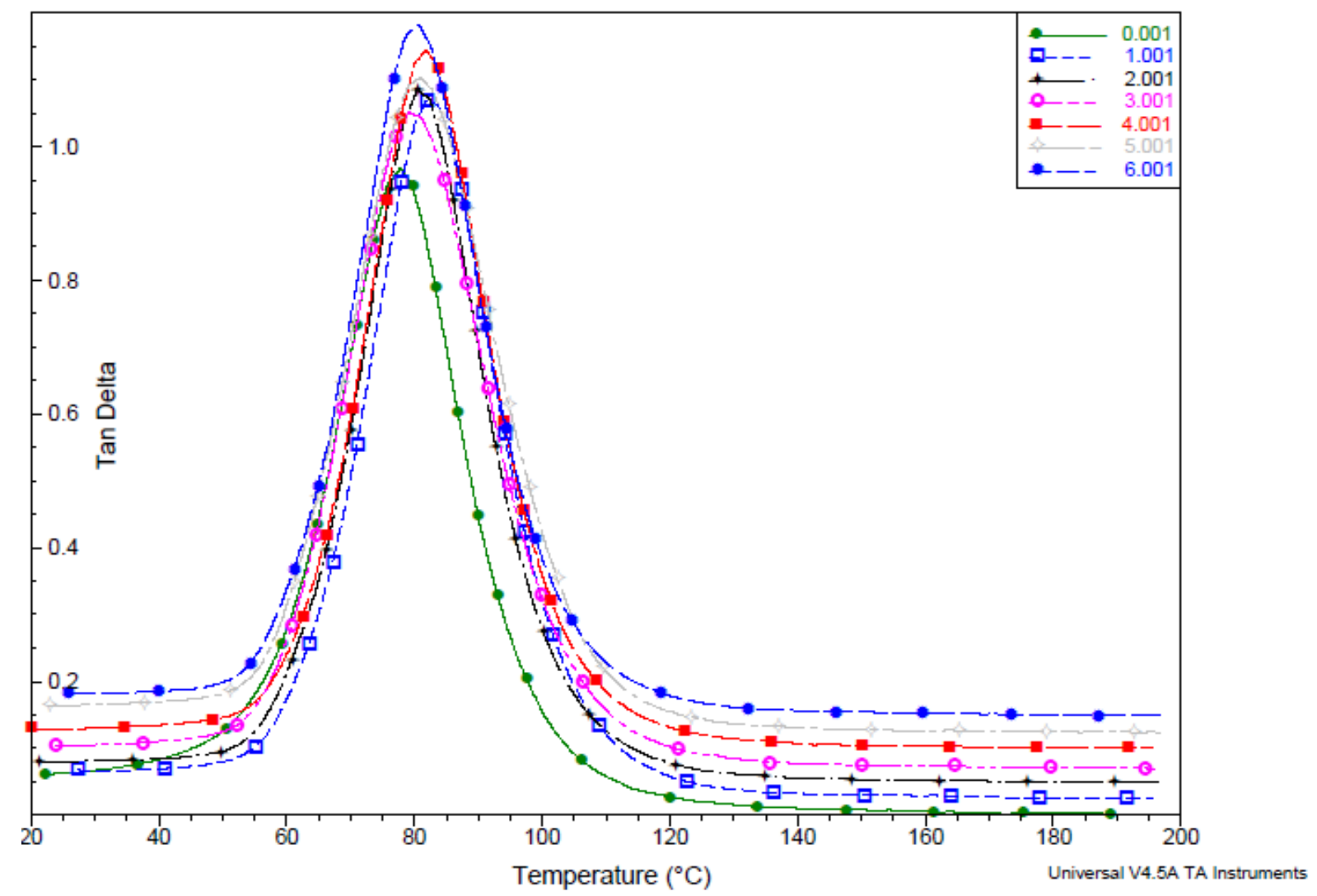

Figure 9: Tan $\delta$ of the BHN Friction Materials as a Function of Temperature 0.001 (CONTR), 1.001 (BHN 1), 2.001 (BHN 2), 3.001 (BHN 3), 4.001(BHN 4), 5.001 (BHN 5), 6.001 (BHN 6)

In this area, the BHN materials have outstanding damping characteristics. It was also noted that the peak moved towards the lower temperature side with an increase in graphite nanoparticle reinforcement. Besides, at the temperatures between $105^{\circ} \mathrm{C}$ and $190{ }^{\circ} \mathrm{C}$, the storage/loss modulus became as low as CONTR, and the BHN Tan $\delta$ magnitude became minimal.

\section{CONCLUSIONS}

BHN brake pads containing CNS were produced, and their thermo-mechanical properties were evaluated. The thermomechanical analysis of BHN brake pad materials yielded the following important results. The mechanical properties of the BHN brake pad materials investigated were within the industry-standard range. The compressive strength of the BHN brake pads were higher than CONTR by $43.7 \%$. The CONTR brake pad's impact resistance was $17.6 \mathrm{KJ} / \mathrm{m}^{2}$, while the BHN brake pads' impact strength varied with the formulation. The SEM results revealed micro-cracks on BHN 4 and BHN 5 fractured surfaces, while surface degradation was observed on BHN 1 and interlocking structure observed on BNH 3 and BHN 6.

The TGA curve showed that adding CNS to the resin matrix greatly improved the materials' thermal stability, but CONTR also showed excellent thermal stability. The BHN brake pads' thermal stability increased as the CNS content increased with a corresponding decrease in graphite nanoparticle content. From the DMA result, the integration of CNS into nanocomposite friction material led to improved storage modulus, loss modulus, and damping factor when sufficient graphite nanoparticles were added. The modulus and damping properties of the BHN brake pad materials showed a significant increase in graphite nanoparticle reinforcement and temperature variation. The storage modulus plots showed 
the heterogeneity present in the BHN brake pads. At a temperature range between $90^{\circ} \mathrm{C}$ and $190{ }^{\circ} \mathrm{C}$, all the material failed and resulted to zero loss modulus. Tan $\delta$ has a lower magnitude throughout the formulation at the temperature range $20^{\circ} \mathrm{C}$ to $55^{\circ} \mathrm{C}$, which was due to the supremacy of the storage modulus over the loss modulus.

\section{REFERENCES}

1. A. O. A. Ibhadode and I. M. Dagwa, "Development of asbestos-free friction lining material from palm kernel shell," J. Braz. Soc. Mech. Sci. Eng., vol. 1, no. 1, pp. 1-2, 2008.

2. D. Shinde and K. Mistry, "Asbestos base and asbestos free brake lining materials: Comparative study," World Scientific News, vol. 61, no. 2, pp. 192-198, 2017.

3. V. Mahale, J. Bijwe, and S. Sinha, "Influence of nano-potassium titanate particles on the performance of NAO brake-pads," Wear, vol. 376, pp. 727-737, 2017.

4. M. Polajnar, M. Kalin, I. Thorbjornsson, J. T. Thorgrimsson, N. Valle, and A. Botor-Probierz, "Friction and wear performance of functionally graded ductile iron for brake pads, "Wear, vol. 382, pp. 85-94, 2017.

5. O. J. Gbadeyan and K. Kanny, "Tribological behaviors of polymer-based hybrid nanocomposite brake pad," Journal of Tribology, vol. 140, no. 3, 2018.

6. J. O. Agunsoye, S. A. Bello, A. A. Bamigbaiye, K. A. Odunmosu, and I. O. Akinboye, "Recycled ceramic composite for automobile brake pad application," Journal of Research in Physics, vol. 39, no. 1, p. 35, 2018.

7. C. Menapace, M. Leonardi, G. Perricone, M. Bortolotti, G. Straffelini, and S. Gialanella, "Pin-on-disc study of brake friction materials with ball-milled nanostructured components, "Materials \& Design, vol. 115, pp. 287-298, 2017.

8. A. Ganguly and R. George, "Asbestos free friction composition for brake linings," Bulletin of Materials Science, vol. 31, no. 1, pp. 19-22, 2008.

9. K. H. Cho, M. H. Cho, S. J. Kim, and H. Jang, "Tribological properties of potassium titanate in the brake friction material; morphological effects," Tribology letters, vol. 32, no. 1, pp. 59-66, 2008.

10. [D. Chan and G. Stachowiak, "Review of automotive brake friction materials," Proceeding of the Institution of Mechanical Engineers, Part D: J. Auto. Eng. , vol. 218, pp. 953-966, 2004.

11. M. Cho, S. Kim, R. Basch, J. Fash, and H. Jang, "Tribological study of gray cast iron with automotive brake linings: The effect of rotor microstructure," Tribology International, vol. 36, no. 7, pp. 537-545, 2003.

12. S. S. Bernard and L. Jayakumari, "Pressure and temperature sensitivity analysis of palm fiber as a biobased reinforcement material in brake pad," Journal of the Brazilian Society of Mechanical Sciences and Engineering, vol. 40, no. 3, p. 152, 2018.

13. R. Yun, P. Filip, and Y. Lu, "Performance and evaluation of eco-friendly brake friction materials," Tribology International, vol. 43, no. 11, 2010.

14. K. N. Kumar and K. Suman, "Review of brake friction materials for future development," J Mech Mech Eng, vol. 3, pp. 1-29, 2017.

15. J. Bijwe, "Composites as friction materials: Recent developments in non-asbestos fiber reinforced friction materials-a review," Polymer composites, vol. 18, no. 3, pp. 378-396, 1997.

16. J. Bijwe and M. Kumar, "Optimization of steel wool contents in non-asbestos organic (NAO) friction composites for best 
combination of thermal conductivity and tribo-performance," Wear, vol. 263, no. 7-12, pp. 1243-1248, 2007.

17. G. Ingo, M. D'uffizi, G. Falso, G. Bultrini, and G. Padeletti, "Thermal and microchemical investigation of automotive brake pad wear residues," Thermochimica acta, vol. 418, no. 1-2, pp. 61-68, 2004.

18. V. Malhotra, P. Valimbe, and M. Wright, "Effects of fly ash and bottom ash on the frictional behavior of composites," Fuel, vol. 81, no. 2, pp. 235-244, 2002.

19. K. Ikpambese, D. Gundu, and L. Tuleun, "Evaluation of palm kernel fibers (PKFs) for production of asbestos-free automotive brake pads," Journal of King Saud University-Engineering Sciences, vol. 28, no. 1, pp. 110-118, 2016.

20. Y. Lu, "A combinatorial approach for automotive friction materials: combined effects of ingredients on friction performance," Polymer composites, vol. 23, no. 5, pp. 814-823, 2002.

21. T. Singh, A. Patnaik, B. K. Satapathy, and M. Kumar, "Performance analysis of organic friction composite materials based on carbon nanotubes-organic-inorganic fibrous reinforcement using hybrid AHP-FTOPSIS approach," Composites: Mechanics, Computations, Applications: An International Journal, vol. 3, no. 3, 2012.

22. T. SINGH, A. PATNAIK, B. SATAPATHY, and B. TOMAR, "Development and optimization of hybrid friction materials consisting of nanoclay and carbon nanotubes by using analytical hierarchy process $(A H P)$ and technique for order preference by similarity to ideal solution (TOPSIS) under fuzzy atmosphere," Walailak Journal of Science and Technology (WJST), vol. 10, no. 4, pp. 343-362, 2013.

23. T. Singh, A. Patnaik, B. Gangil, and R. Chauhan, "Optimization of tribo-performance of brake friction materials: effect of nano filler," Wear, vol. 324, pp. 10-16, 2015.

24. J. S. Raj, T. Christy, S. D. Gnanaraj, and B. Sugozu, "Influence of calcium sulfate whiskers on the tribological characteristics of automotive brake friction materials," Engineering Science and Technology, an International Journal, vol. 23, no. 2, pp. 445-451, 2020.

25. S. Jeganmohan, B. Sugozu, M. Kumar, and D. R. Selvam, "Experimental investigation on the friction and wear characteristics of palm seed powder reinforced brake pad friction composites," Journal of The Institution of Engineers (India): Series D, vol. 101, no. 1, pp. 61-69, 2020.

26. A. Patnaik, M. Kumar, B. K. Satapathy, and B. S. Tomar, "Performance sensitivity of hybrid phenolic composites in friction braking: effect of ceramic and aramid fibre combination," Wear, vol. 269, no. 11-12, pp. 891-899, 2010.

27. N. Dadkar, B. S. Tomar, B. K. Satapathy, and A. Patnaik, "Performance assessment of hybrid composite friction materials based on flyash-rock fibre combination," Materials \& Design, vol. 31, no. 2, pp. 723-731, 2010.

28. J. Bijwe, N. Majumdar, and B. Satapathy, "Influence of modified phenolic resins on the fade and recovery behavior of friction materials, "Wear, vol. 259, no. 7-12, pp. 1068-1078, 2005.

29. B. Satapathy and J. Bijwe, "Performance of friction materials based on variation in nature of organic fibres: Part I. Fade and recovery behaviour," Wear, vol. 257, no. 5-6, pp. 573-584, 2004.

30. B. Satapathy and J. Bijwe, "Fade and recovery behavior of non-asbestos organic (NAO) composite friction materials based on combinations of rock fibers and organic fibers," Journal of reinforced plastics and composites, vol. 24, no. 6, pp. 563-577, 2005 .

31. M. H. Cho, J. Ju, S. J. Kim, and H. Jang, "Tribological properties of solid lubricants (graphite, Sb2S3, MoS2) for automotive brake friction materials," Wear, vol. 260, no. 7-8, pp. 855-860, 2006.

32. D. Chan and G. Stachowiak, "Review of automotive brake friction materials," Proceedings of the Institution of Mechanical 
Engineers, Part D: Journal of Automobile Engineering, vol. 218, no. 9, pp. 953-966, 2004.

33. B. Wielage, T. Lampke, G. Marx, K. Nestler, and D. Starke, "Thermogravimetric and differential scanning calorimetric analysis of natural fibres and polypropylene," Thermochimica Acta, vol. 337, no. 1-2, pp. 169-177, 1999.

34. O. J. Gbadeyan, "Low friction hybrid nanocomposite material for brake pad application," 2017.

35. O. E Ige, F. L Inambao, and G. A Adewumi, "Synthesis of Natural Carbon Nanospheres From Palm Kernel Fiber," International Journal of Mechanical Engineering and Technology, vol. 10, no. 12, pp. 625-641, 2019.

36. D. ASTM, "Standard Test Method for Rigid Plastics," in American Society for Testing and Materials, 2006, vol. D 695-2a,, ed, 2006 ed.

37. S. Pesetskii, S. Bogdanovich, and N. Myshkin, "Tribological behavior of nanocomposites produced by the dispersion of nanofillers in polymer melts, "Journal of Friction and Wear, vol. 28, no. 5, pp. 457-475, 2007.

38. F.-h. Su, Z.-z. Zhang, and W.-m. Liu, "Mechanical and tribological properties of carbon fabric composites filled with several nano-particulates, " Wear, vol. 260, no. 7-8, pp. 861-868, 2006.

39. S. Bhaskar, M. Kumar, and A. Patnaik, "Microstructure, Thermal, Thermo-mechanical and Fracture Analyses of Hybrid AA2024-SiC Alloy Composites," Transactions of the Indian Institute of Metals, vol. 73, no. 1, pp. 181-190, 2020.

40. J. Olusanya, K. Kanny, and S. Singh, "Bulk cure study of nanoclay filled epoxy glass fiber reinforced composite material," Journal of Polymer Engineering, vol. 37, no. 3, pp. 247-259, 2017.

41. I. Lawrence and U. Paul, "Critical evaluation/reassessment of (abfm) automotive brake friction materials, "Standard Research Journal, 2013.

42. O. J. Gbadeyan, K. Kanny, and T. Mohan, "Influence of the multi-walled carbon nanotube and short carbon fibre composition on tribological properties of epoxy composites, "Tribology-Materials, Surfaces \& Interfaces, vol. 11, no. 2, pp. 59-65, 2017.

43. S. Parveen, S. Rana, and R. Fangueiro, "A review on nanomaterial dispersion, microstructure, and mechanical properties of carbon nanotube and nanofiber reinforced cementitious composites, "Journal of Nanomaterials, vol. 2013, 2013.

44. A. A. Koval'chuk, V. G. Shevchenko, A. N. Shchegolikhin, P. M. Nedorezova, A. N. Klyamkina, and A. M. Aladyshev, "Effect of carbon nanotube functionalization on the structural and mechanical properties of polypropylene/MWCNT composites," Macromolecules, vol. 41, no. 20, pp. 7536-7542, 2008.

45. D. Matykiewicz, M. Barczewski, D. Knapski, and K. Skórczewska, "Hybrid effects of basalt fibers and basalt powder on thermomechanical properties of epoxy composites," Composites Part B: Engineering, vol. 125, pp. 157-164, 2017.

46. M. Kumar and A. Kumar, "Thermomechanical analysis of hybrid friction composite material and its correlation with friction braking performance, "International Journal of Polymer Analysis and Characterization, vol. 25, no. 2, pp. 65-81, 2020. 